Previous studies have suggested that alveolar macrophages (AMs) and T cells are associated with the pathogenesis of ILD. Recently, it is reported that coinhibitory molecules are expressed at the site of inflammation such as RA synovium; however, detailed lung immunophenotyping has not been reported.

Objectives: To identify immunologic factors in the lungs of patients with RA-associated ILD (RA-ILD) and IIM-associated ILD (IIM-ILD) and to examine their pathological mechanisms.

Methods: A total of 11 patients with RA-ILD, 16 with IIM-ILD, and 6 with drug-induced ILD (DI-ILD) and 8 healthy controls were enrolled. Peripheral blood and bronchoalveolar lavage fluid (BALF) were immunophenotyped by flow cytometry. AMs were analyzed by RNA-sequence and coculture assay with peripheral naïve CD4+ T cells of healthy individuals.

Results: Several coinhibitory molecules were coexpressed on BALF T cells in the order of CTLA-4, PD-1, Tim-3, and LAG-3 from most to least, whereas only PD-1 was expressed on peripheral T cells among them. In RA-ILD, PD-1+ and Tim-3+ CD4+ T cells in the BALF were increased. PD-1+CD4+ T cells populations correlated differentiated $B$ cells and Tim-3+CD4+ T cells populations correlated with ILD severity and RF titer. In contrast, in IIM-ILD, activated CD8+ $T$ cells were increased and they coexpressed CTLA-4, PD-1 and Tim-3. BALF $\mathrm{PD}-1+\mathrm{CD} 4+\mathrm{T}$ cells rarely expressed CXCR5, and they positively correlated with plasmablasts and plasma cells, indicating most of them are considered Tph cells. In the coculture experiments, AMs of RA-ILD and IIM-ILD induced more PD-1 and Tim-3 on CD4+ T cells, suggesting that coinhibitory molecule expression on BALF T cells was partly due to AMs. In RNA-sequence, PD-ligand (PD-L) 1 and PD-L2 genes were significantly downregulated in AMs from RA-ILD compared with DI-ILD.

Conclusion: We identified $\mathrm{T}$ cell subsets that play a central role in the pathogenesis of RA-ILD and IIM-ILD; PD-1 on T cells in RA-ILD and Tim-3 on CD8+ $T$ cells in IIM-ILD might be key factors in the disease process. The evaluation of coinhibitory molecules on BALF T cells could be clinically useful.

Disclosure of Interests: Maho Nakazawa: None declared, Katsuya Suzuki: None declared, Masaru Takeshita: None declared, Jun Inamo: None declared, Hirofumi Kamata: None declared, Makoto Ishii: None declared, Yoshitaka Oyamada: None declared, Hisaji Oshima: None declared, Tsutomu Takeuchi Grant/ research support from: Eisai Co., Ltd, Astellas Pharma Inc., AbbVie GK, Asahi Kasei Pharma Corporation, Nippon Kayaku Co., Ltd, Takeda Pharmaceutical Company Ltd, UCB Pharma, Shionogi \& Co., Ltd., Mitsubishi-Tanabe Pharma Corp., Daiichi Sankyo Co., Ltd., Chugai Pharmaceutical Co. Ltd., Consultant of: Chugai Pharmaceutical Co Ltd, Astellas Pharma Inc., Eli Lilly Japan KK, Speakers bureau: AbbVie GK, Eisai Co., Ltd, Mitsubishi-Tanabe Pharma Corporation, Chugai Pharmaceutical Co Ltd, Bristol-Myers Squibb Company, AYUMI Pharmaceutical Corp., Eisai Co., Ltd, Daiichi Sankyo Co., Ltd., Gilead Sciences, Inc., Novartis Pharma K.K., Pfizer Japan Inc., Sanofi K.K., Dainippon Sumitomo Co., Ltd.

DOI: 10.1136/annrheumdis-2020-eular.4542

\section{THU0050 CXCL13 IS A KEY DRIVER FOR MIGRATION AND DIFFERENTIATION OF REGULATORY B CELLS}

C. Rempenault ${ }^{1}$, K. Schreiber ${ }^{1}$, J. Mielle ${ }^{2}$, P. Corbeau ${ }^{3}$, J. Morel ${ }^{1}$, C. Daien ${ }^{1,2}$, R. Audo ${ }^{2} .{ }^{1} \mathrm{CHU}$ and University of Montpellier, Rheumatology, Montpellier, France; ${ }^{2}$ CNRS IGMM UMR5535, Montpellier, France; ${ }^{3}$ mmunology, Nîmes, France

Background: Regulatory B cells in human still need to be characterized. Given the absence of a phenotypical definition of these cells, a functional definition based on their ability to secrete IL-10 is often used (corresponding to $\mathrm{B} 10+$ cells). Chemokine receptors $(\mathrm{CKR})$ profiles are useful to characterize some populations of $\mathrm{T}$ cells but have never been explored among $\mathrm{B}^{+} 0^{+}$cells.

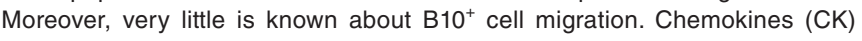
have also been implicated in the differentiation of naïve $T$ cells towards regulatory $T$ cells.

Objectives: Therefore, the aims of our study were to first characterize the profile of $\mathrm{CKR}$ on $\mathrm{B}^{+} 0^{+}$cells, and second to investigate $\mathrm{CK}$ implicated in their migration and differentiation, this, both in control (CTL) and in patients with rheumatoid arthritis (RA).

Methods: B cells were isolated with Rosette Sep Human B cells enrichment followed by Ficoll separation. B cells were then activated 24 hours with $\mathrm{CpG}$ and CD40L to generate B10 ${ }^{+}$cells. IL-10 secretion from $B$ cells was assessed by FACs and ELISA. We compared the expression of several CKR between $\mathrm{B}^{+} 0^{+}$and $\mathrm{IL}-10^{\text {neg }} \mathrm{B}$ cells $\left(\mathrm{B} 10^{\text {neg }}\right)$ from $\mathrm{CTL}$ and RA patients by flow cytometry. For migration assay, $\mathrm{B}^{+} 0^{+}$and $\mathrm{B} 10^{\text {neg }}$ cells were sorted by FACSaria. Their ability to migrate, in response to ligand of CKR found differentially expressed in the first part (CCL21, CCL22, CXCL11, CXCL12 or CXCL13) or synovial fluid (SF) from RA patients, were evaluated by migration assay in $5 \mu \mathrm{M}$ Transwell chambers and expressed as fold increase compare to basal migration towards control media.

Results: $\mathrm{B}^{+} 0^{+}$cells expressed a different profile of $\mathrm{CKR}$ compared to $\mathrm{B} 10^{\text {neg }}$ both in CTL and RA patients and these profiles differed between $\mathrm{B}^{+} 0^{+}$cells of CTL and RA patients. However, no CKR profile could phenotypically define

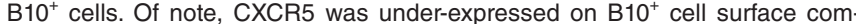

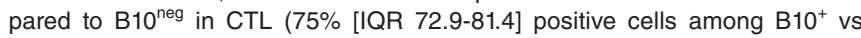
$99.2 \%$ [98.4-99.4] positive cells among $\left.B 10^{\text {neg }}, p=0.006, n=10\right)$ and also in RA patients (78.3\% [70.8-82.3] vs $98.2 \%$ [96.9-99.54, $p=0.008, n=8)$. Nevertheless, mRNA expression of CXCR5 was higher among $\mathrm{B}^{1} 0^{+}$versus $\mathrm{B} 10^{\text {neg }}$ cells in CTL and RA patients. As CpG-stimulated cells over-expressed CXCL13, ligand of CXCR5, we hypothesized that the binding of its ligand induced the internalisation of CXCR5. Indeed, among all CK tested, only CXCL13, attracted significantly more $\mathrm{B}^{+} 0^{+}$than $\mathrm{B} 10^{\text {neg }}$ from $\mathrm{CTL}(9.1[5.6-14.6]$ fold increase migration of $\mathrm{B}^{+} 0^{+}$vs 5.2 [3.1-7.5] fold increase migration of $\mathrm{B} 10^{\text {neg }}, \mathrm{p}<0.0001, \mathrm{n}=21$ ). This was also true in RA patients (10.9 [3.6-29.9] fold increase migration of $\mathrm{B}^{+} 0^{+}$ vs $4.8[2.1-7.7]$ fold increase migration of $\left.B 10^{\text {neg }}, p=0.009, n=12\right)$. SF from RA patients induced a significant migration of $\mathrm{B}^{+} 0^{+}$cells in CTL (7.3-fold increase [4.1-21.7], $p=0.004, n=9$ ) and $R A$ patients (5.7-fold increase [2.3-7.9], $p=0.008$, $\mathrm{n}=10)$. This migration was correlated with the levels of CXCL13 in these SF, in CTL $(r=0.7, p=0.05, n=9)$ but not in RA patients $(n=10)$. Lastly, CXCL13 was also found to increase IL-10 secretion in B cells stimulated with CpG in CTL (1.5-fold increase [1.3-1.5], $p=0.0002, n=13)$ and in RA patients (1.2-fold increase [1.11.3], $\mathrm{p}=0.005, \mathrm{n}=12$ ).

Conclusion: We showed that $\mathrm{CXCL} 13$ is a key driver for migration and differentiation of $\mathrm{B} 10+$ cells in CTL and in RA patients. However, the migration of $\mathrm{B}^{+} 0^{+}$ cells in RA patients was not correlated with the level of CXCL13 in SF from RA patients, suggesting the implication of other $\mathrm{CK}$ in the migration of $\mathrm{B}^{+} 0^{+}$cells in RA.

Disclosure of Interests: None declared

DOI: 10.1136/annrheumdis-2020-eular.3544

\section{THU005 LOW-DOSE INTERLEUKIN-2 SELECTIVELY EXPAND AND ACTIVATE REGULATORY T CELLS ACROSS 13 AUTOIMMUNE DISEASES.}

M. Rosenzwajg ${ }^{1}$, R. Lorenzon ${ }^{2}$, P. Cacoub ${ }^{3}$, F. Pitoiset ${ }^{4}$, S. Aractingi ${ }^{5}$, B. Banneville ${ }^{6}$, L. Beaugerie ${ }^{7}$, F. Berenbaum ${ }^{7}$, J. Champey ${ }^{7}$

O. Chazouilleres ${ }^{7}$, C. Corpechot ${ }^{7}$, B. Fautrel ${ }^{6}$, A. Mekinian ${ }^{7}$, E. Regnier ${ }^{7}$, D. Saadoun ${ }^{6}$, J. E. Salem ${ }^{6}$, J. Sellam ${ }^{7}$, P. Seksik ${ }^{7}$, D. Klatzmann ${ }^{1} .{ }^{1}$ Sorbonne Université, Biotherapy, Paris, France; ${ }^{2}$ Sorbonne Université, Paris, France; ${ }^{3}$ APHP, Internal Medicine and Clinical Immunology, Paris, France; ${ }^{4}$ Sorbonne Université, Paris, France; ${ }^{5}$ APHP, Paris, France; ${ }^{5}$ APHP, Paris, France; ${ }^{7}$ APHP, Paris, France

Background: Regulatory T cells (Tregs) prevent autoimmunity and control inflammation. As low-dose interleukin-2 (Id-IL2) expands and activates Tregs, it has a broad therapeutic potential for any autoimmune or inflammatory disease (AIID) We performed a disease-finding "basket trial" (TRANSREG NCT01988506) in patients affected by one of 11 different AIID and reported the outcome of the first 46 patients (Rosenzwajg et al, ARD 2019).

Objectives: Here we analyzed and discussed results from deep immunophenotyping, of 78 patients, to comprehensively study the effect of Id-IL2 on the immune system of patients affected by various AIID

Methods: We performed a prospective, open label, phase I-Ila study in 78 patients with a mild to moderate form of one of 13 selected AIID. All patients received Id-IL2 ( 1 million IU/day) for 5 days, followed by fortnightly injections for 6 months. Deep immunophenotyping was performed before and after 5 days of Id-IL2.

Results: Id-IL2 significantly expands both memory Tregs as well as naïve Tregs, including recent thymic emigrant Tregs. It also activates Tregs as demonstrated by the significantly increased expression of HLA-DR, CD39, CD73, GITR, CTLA4. Similar results were observed across the different AIID.

Conclusion: Id-IL2 "universally" improves Treg fitness across 13 autoimmune and inflammatory disease.

References:

[1] Rosenzwajg M\#, Lorenzon R\#, Cacoub P, Pham HP, Pitoiset F, El Soufi K Rlbet C, Bernard C, Aractingi S, Banneville B, Beaugerie L, Berenbaum F Champey J, Chazouilleres O, Corpechot C, Fautrel B, Mekinian A, Regnier E, Saadoun D, Salem JE, Sellam J, Seksik P, Daguenel-Nguyen A, Doppler V, Mariau J, Vicaut E, Klatzmann D. Immunological and clinical effects of low-dose interleukin-2 across 11 autoimmune diseases in a single, open clinical trial. Ann Rheum Dis. 2019 Feb;78(2):209-217. doi: 10.1136/annrheumdis-2018-214229. Epub 2018 Nov 24

Disclosure of Interests: Michelle Rosenzwajg: None declared, Roberta Lorenzon: None declared, Patrice cacoub: None declared, Fabien Pitoiset: 